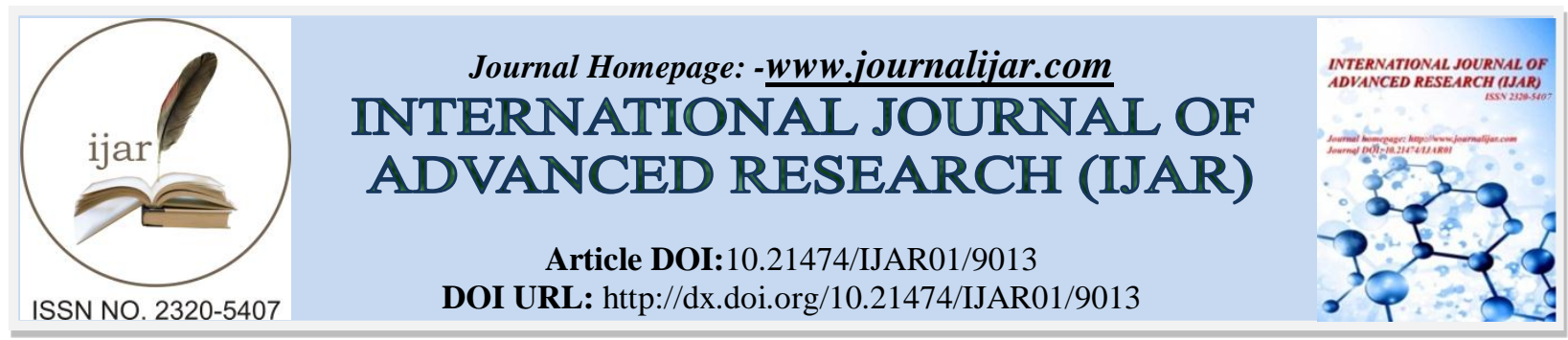

RESEARCH ARTICLE

\title{
ILEOCOLIC INTUSSUSCEPTION CAUSED BY A LIPOMA IN AN ADULT.
}

\section{Dr. Siddhartha Reddy $A^{1}$, Dr. Ganesh $P^{2}$ and Dr. Sankar $S^{3}$.}

1. Resident, Department of Medical gastroenterology, Sri Ramachandra Institute of Higher Education and Research, Chennai, India.

2. Head of the department, Department of Medical gastroenterology, Sri Ramachandra Institute of Higher Education and Research, Chennai, India.

3. Head of the department, Department of Surgical gastroenterology, Sri Ramachandra Institute of Higher Education and Research, Chennai, India.

\section{Manuscript Info}

Manuscript History

Received: 02 March 2019

Final Accepted: 04 April 2019

Published: May 2019

\section{Abstract}

Intussusception rarely observed in adults accounts for only $5 \%$ of all the cases and almost 1\%-5\% of bowel obstruction cases. The aetiology, presentation and management in adults are different from those in children. The clinical presentation in adults often includes nonspecific signs and symptoms, thereby complicating differential diagnosis from other causes of abdominal pain. We report a case of 47year-old Asian man who presented to the OPD with complaints of recurrent crampy type of lower abdominal pain for the past 4 years. Colonoscopy showed ileocolonic intussusception with overlying mass extending up to splenic flexure with spontaneous regression. Abdominal CT demonstrated ileocolic intussusception, and hence segmental ileo-colonic resection was done and ileo-ascending colon was anastomosed. Histopathology report of the resected specimen confirmed a sub mucosal lipoma measuring $4.5 \mathrm{~cm}$ with extensive fat necrosis. Proper vigilance and appropriate investigations help in prompt diagnosis and surgical referral help enable favourable outcomes.

Copy Right, IJAR, 2019,. All rights reserved.

\section{Introduction:-}

Intussusception of the bowel is defined as a condition in which a proximal bowel segment (intussusceptum) invaginates into an adjacent distal segment (intussuscipiens), thereby causing bowel obstruction ${ }^{[1]}$. It is a rare cause of abdominal pain in the adults, accounting for only $1 \%-5 \%$ of all cases of intestinal obstructions and $5 \%$ of all cases of intussusception ${ }^{[2-4]}$. The clinical presentation is usually nonspecific. Early diagnosis, appropriate treatment including surgery can be performed and hence has resulted in the mortality rate from being less than $1 \%{ }^{[5]}$. This is a case of a 47 old Asian man who was diagnosed to have ileocolic intussusception with lipoma being the lead point and resected by an open surgery.

\section{Case Report}

A 47-year-old Asian man who is a known smoker for the past 12 years has presented to the out patient department with complaints of recurrent lower abdominal pain for the past 4 years. It was gradual in onset, progressive, 
intermittent in nature with no aggravating and relieving factors. Pain was associated with bloating sensation and post prandial distress. Furthermore, he denied any history of diarrhoea, melena, hematochezia, weight gain or loss and bowel habit change. His past history was insignificant. On physical examination his abdomen was soft, non tender, with no visible or palpable masses. The other examination results were normal.

The blood counts, renal function tests, serum electrolytes were within the normal ranges. Plain abdominal radiograph was performed and showed no signs of obstruction or perforation. Colonoscopy done showed an ulcerative mass with mucosal erythema and oedema at splenic flexure. And on further negotiation of the scope, the mass showed spontaneous regression and reduced till caecum.

Computed tomography of whole abdomen plain and contrast showed a large ileocolonic intussusception on the right side extending upto mid transverse colon having target appearance. Few intramural pockets were seen within the thickened wall. Post contrast images showed mural oedema, stratification with layered pattern of enhancement within the intussuscipiens. Few nodes were visualised within the intussuscepted segment, largest measuring $1.7 * 1.2 \mathrm{~cm}$.

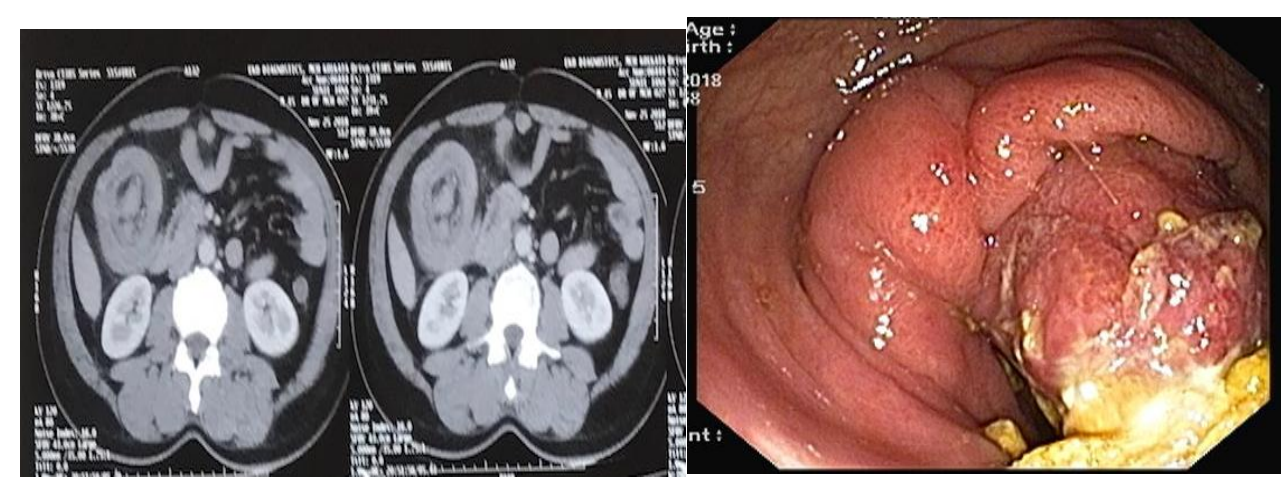

Figure1:-CT showing targeted appearance on the right side suggestive of intussusception; Figure 2: Ulcerative mass with overlying faecal matter

Surgical gastroenterology team was consulted and the patient was taken up for open segmental ileo-colonic resection with ileo-ascending colon anastomosis. Histopathology report of the resected segment confirmed a sub mucosal lipoma measuring $4.5 \mathrm{cms}$ with extensive fat necrosis. Patient was monitored and on being stable was discharged on postoperative day 5 without complications. He was followed up a week later and periodically showed no symptoms.

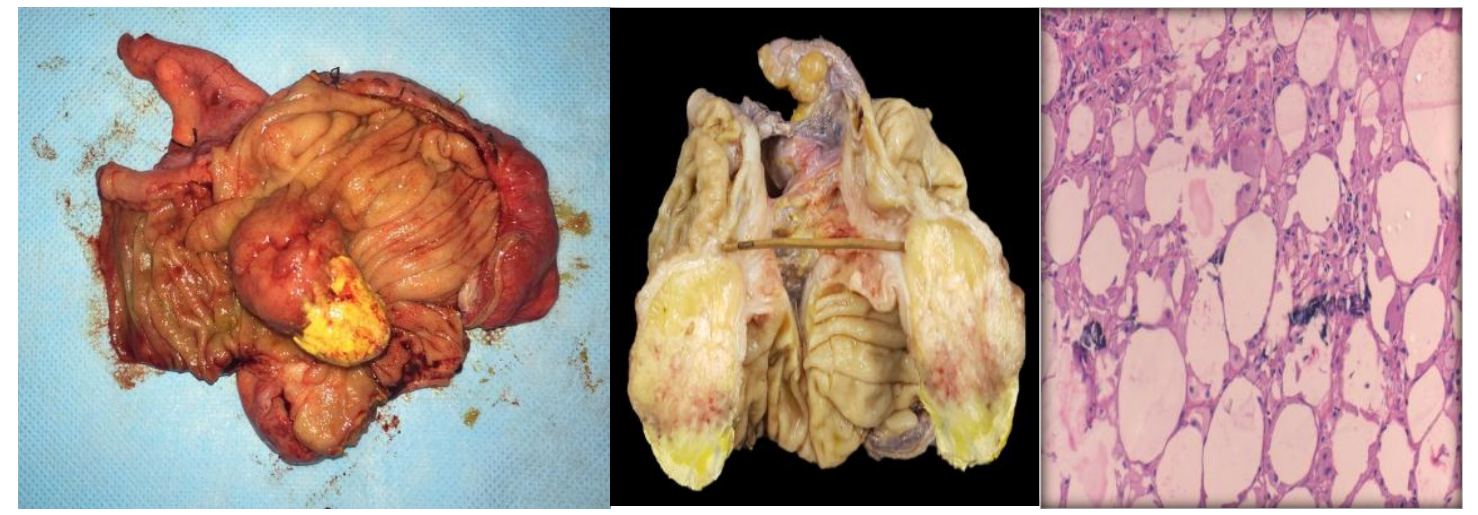

Figure 1:-Resected specimen from colon containing the lipoma with overlying faecal matter; Figure 2:-Gross image of resected specimen - there is sub mucosal well circumscribed lesion yellow in color, greasy soft in consistency; Figure 3:-HPE of resected specimen showing adipocytes with peripherally pushed nucleus and foamy macrophages indicating fat necrosis

\section{Discussion:-}

Intussusception is common in children and in those under the age of three. Overall, the male-to-female ratio is 3:1. With advancing age, the sexual difference becomes marked. In patients older than four years, the male-to-female 
ratio is $8: 1^{[6,7]}$. The aetiology, presentation and management of intussusception in adults are different from those of children. In children, intussusception is usually idiopathic or secondary to viral illness. And furthermore, the ileocecal valve may function as the lead point in ileocecal intussusception ${ }^{\text {[8] }}$. In the adult population, primary or idiopathic intussusception accounts for about $8 \%-20 \%$ of cases ${ }^{[9,10]}$. Secondary intussusception, which is more common, is associated with a pathological lesion involving a lead point, which can be a benign polyp, enlarged mesenteric lymph node, lipoma, appendix, Meckel's diverticulum, or malignant tumours, such as lymphoma, gastrointestinal stromal tumour, primary or metastatic adenocarcinoma ${ }^{[4,10,11]}$. Lipomas may occur throughout the intestinal tract, but occur most frequently in the colon. Intussusception can be classified into four types depending on its location: (1) entero-enteric, involving the small intestine; (2) colo-colic, involving the large intestine; (3) ileo-colic, involving the terminal ileum and ascending colon; and (4) ileo-cecal, involving the ileo-cecal valve as the lead point ${ }^{[4,12]}$.

Early diagnosis of adult intussusception is difficult because most cases present with non-specific signs and symptoms as well as have a chronic, sub-acute or acute course. The classic triad of intermittent abdominal pain, currant jelly stools, and a palpable tender mass seen in children is rarely present in adults. However, in adults, nausea, vomiting, gastrointestinal bleeding, changes in bowel habits and abdominal distension are more common $^{[9,11]}$. Adult intussusceptions are detected using plain abdominal film, barium studies, colonoscopy, abdominal sonography, abdominal CT and magnetic resonance imaging ${ }^{[11,13,14]}$. Although there are several diagnostic imaging techniques, as mentioned above, an abdominal CT scan is the most commonly used and accurate diagnostic modality ${ }^{[9,13-15]}$. CT shows "target" or "sausage" shaped lesions, while also defining the location, nature and relationship of the lesion to surrounding tissues with an accuracy that ranges from $60 \%$ to $100 \%{ }^{[3,9,13,15]}$. Abdominal ultrasonography has also been successful in diagnosing intussusception, especially if a palpable mass is found ${ }^{[16]}$.

Adult intussusception is associated with a pathological lesion involving a lead point. Therefore, surgical intervention is mandatory. Most surgeons accept that adult intussusception requires surgical intervention because of the large proportion of structural anomalies and the high incidence of occurring malignancy ${ }^{[4]}$.

Endoscopic resection has been reported, but it can result in unfavourable complications, including perforation or haemorrhage. Surgical resection is commonly recommended to remove the lead point, such as lipomas that are larger than 2-cm in diameter ${ }^{[17]}$.

Ileocolic intussusception is a rare cause of abdominal pain in adults that can often be elusive due to the frequent lack of peritoneal irritation signs and specific symptoms. Complications associated with intussusception, which rarely occur when the diagnosis is prompt, include perforation during non-operative reduction, wound infection, sepsis from undetected peritonitis (which is a major complication that occurs following a missed diagnosis), necrosis, bowel perforation and recurrence. While intussusception itself has good prognosis, the main prognostic factor affecting the course of the disease is the nature of the causative lesion. Mortality for adult intussusception increases from $8.7 \%$ of cases with benign lesions to $52.4 \%$ of cases with malignant lesions ${ }^{[9]}$.

A sufficient level of vigilance and appropriate investigations are important for a prompt diagnosis and surgical referral of patients for a favourable outcome.

\section{References:-}

1. Ghaderi H, Jafarian A, Aminian A, Mirjafari Daryasari SA. Clinical presentations, diagnosis and treatment of adult intussusception, a 20 years survey. Int J Surg 2010; 8: 318-320 [PMID: 20359557 DOI: 10.1016/j.ijsu.2010.02.013]

2. Haas EM, Etter EL, Ellis S, Taylor TV. Adult intussusception. Am J Surg 2003; 186: 75-76 [PMID: 12842754]

3. Barussaud M, Regenet N, Briennon X, de Kerviler B, Pessaux P, Kohneh-Sharhi N, Lehur PA, Hamy A, 
Leborgne J, le Neel JC, Mirallie E. Clinical spectrum and surgical approach of adult intussusceptions: a multicentric study. Int $\mathrm{J}$ Colorectal Dis 2006; 21: 834-839 [PMID: 15951987 DOI: 10.1007/s00384-005-0789-3]

4. Marinis A, Yiallourou A, Samanides L, Dafnios N, Anastasopoulos G, Vassiliou I, Theodosopoulos T. Intussusception of the bowel in adults: a review. World J Gastroenterol 2009; 15: 407-411 [PMID: 19152443 DOI: $10.3748 /$ wjg. 15.407]

5. Stringer MD, Pablot SM, Brereton RJ. Paediatric intussusception. Br J Surg 1992; 79: 867-876 [PMID: 1422744]

6. Shapkina AN, Shapkin VV, Nelubov IV, Pryanishena LT. Intus- susception in children: 11-year experience in Vladivostok. Pediatr Surg Int 2006; 22: 901-904 [PMID: 17021742 DOI: 10.1007/s00383- 006-1764-y]

7. Parashar UD, Holman RC, Cummings KC, Staggs NW, Curns AT, Zimmerman CM, Kaufman SF, Lewis JE, Vugia DJ, Powell KE, Glass RI. Trends in intussusception-associated hospitalizations and deaths among US infants. Pediatrics 2000; 106: 1413-1421 [PMID: 11099597]

8. Rogers SO, Lee MC, Ashley SW. Giant colonic lipoma as lead point for intermittent colo-colonic intussusception. Surgery 2002; 131: 687-688 [PMID: 12075187]

9. Azar T, Berger DL. Adult intussusception. Ann Surg 1997; 226: 134-138 [PMID: 9296505]

10. Begos DG, Sandor A, Modlin IM. The diagnosis and management of adult intussusception. Am J Surg 1997; 173: 88-94 [PMID: 9074370 DOI: 10.1016/S0002-9610(96)00419-9]

11. Eisen LK, Cunningham JD, Aufses AH. Intussusception in adults: institutional review. J Am Coll Surg 1999; 188: 390-395 [PMID: 10195723]

12. Weilbaecher D, Bolin JA, Hearn D, Ogden W. Intussusception in adults. Review of 160 cases. Am J Surg 19

13. Yakan S, Caliskan C, Makay O, Denecli AG, Korkut MA. Intussusception in adults: clinical characteristics, diagnosis and operative strategies. World J Gastroenterol 2009; 15: 1985-1989 [PMID: 19399931 DOI: 10.3748/wjg.15.1985]

14. Chang CC, Chen YY, Chen YF, Lin CN, Yen HH, Lou HY. Adult intussusception in Asians: clinical presentations, diagnosis, and treatment. J Gastroenterol Hepatol 2007; 22: 1767-1771 [PMID: 17914948 DOI: 10.1111/j.1440-1746.2007.04907.x]

15. Smith DS, Bonadio WA, Losek JD, Walsh-Kelly CM, Hennes HM, Glaeser PW, Melzer-Lange M, Rimm AA. The role of abdominal x-rays in the diagnosis and management of intussusception. Pediatr Emerg Care 1992; 8: 325-327 [PMID: 1454638]

16. Reijnen HA, Joosten HJ, de Boer HH. Diagnosis and treatment of adult intussusception. Am J Surg 1989; 158 : 25-28 [PMID: 2662787]

17. Yu JP, Luo HS, Wang XZ. Endoscopic treatment of submucosal lesions of the gastrointestinal tract. Endoscopy 1992; 24: 190-193 [PMID: 1587236 DOI: 10.1055/s-2007-1010460]. 